\title{
Effect of rosuvastatin pretreatment on myocardial damage after coronary surgery: A randomized trial
}

Vito A. Mannacio, MD, ${ }^{a}$ Domenico Iorio, MD, ${ }^{a}$ Vincenzo De Amicis, MD, ${ }^{a}$ Francesco Di Lello, MD, ${ }^{a}$ and F. Musumeci, MD ${ }^{b}$

Objective: Myocardial disease without evidence of myocardial infarction is a frequent complication after cardiac surgery during cardiopulmonary bypass. Statins might be protective, but their efficacy has not been established in randomized trials.

Methods: Two hundred patients undergoing coronary surgery were enrolled. They were randomized to rosuvastatin $(20 \mathrm{mg} / \mathrm{d}, \mathrm{n}=100)$ or placebo $(\mathrm{n}=100)$ starting 1 week before the operation. Troponin I, myoglobin, creatine kinase-MB mass, and high-sensitivity $\mathrm{C}$-reactive protein were used as markers of myocardial injury, and their values were determined at baseline and at regular intervals after the operation. Electrocardiography and echocardiography were performed before and after the operation.

Results: Myocardial disease was diagnosed when troponin I, myoglobin, and creatine kinase-MB mass values were above the upper normal limit without evidence of electrocardiographic changes, echocardiographic changes, or both. The percentages of marker level increase indicative of myocardial disease were determined in the placebo versus statin groups and were as follows: troponin I, $35 \%$ versus $65 \%(P<.0001)$; myoglobin, $39 \%$ versus $72 \%$ $(P<.0001)$; creatine kinase-MB mass, $22 \%$ versus $40 \%(P=.0002)$. Peak postoperative values of troponin I $(0.16 \pm 0.15$ vs $0.32 \pm 0.26 \mathrm{ng} / \mathrm{mL}, P=.0008)$, myoglobin $(72.25 \pm 25 \mathrm{vs} 98.31 \pm 31 \mathrm{ng} / \mathrm{mL}, P<.0001)$, and creatine kinase-MB mass $(3.9 \pm 3.3 \mathrm{vs} 9.3 \pm 8.1 \mathrm{ng} / \mathrm{mL}, P<.0001)$ were significantly higher in the placebo group. High-sensitivity C-reactive protein values were increased in $58 \%$ of pretreated versus $88 \%$ of the control patients $(15.4 \pm 2.5 \mathrm{vs} 17.2 \pm 3.4 \mathrm{mg} / \mathrm{L}, P<.0001)$. In high-risk patients myocardial disease was observed more frequently but significantly less in statin-pretreated patients.

Conclusions: Statin pretreatment reduces myocardial damage after coronary surgery and could improve both short- and long-term results.

Earn CME credits at

http://cme.ctsnetjournals.org
Myocardial damage (MD), as assessed based on biochemical marker increase, occurs very frequently after coronary surgery. ${ }^{1-4}$ Even if marker increase can be observed in more than $60 \%$ of patients, electrocardiographic abnormalities, echocardiographic abnormalities, or both suggestive of myocardial infarction (MI) ${ }^{5,6}$ are detectable in only $1 \%$ to $3 \%$ of them. In most patients cardiac function remains unaltered, yet evidence of MD is a sensible predictor of early and late cardiovascular events. ${ }^{4,7}$ Many clinical and intraoperative factors concur with the pathogenesis of this condition, and recently, the contribution of an in-

\footnotetext{
From the Department of Cardiac Surgery, ${ }^{a}$ University of Naples Federico II, Naples, Italy, and the Department of Cardiovascular Surgery, ${ }^{b}$ Azienda Ospedaliera S. Camillo Forlanini, Rome, Italy.

Received for publication Feb 7, 2008; revisions received May 23, 2008; accepted for publication June 19, 2008.

Address for reprints: Vito A. Mannacio, MD, Via S. Domenico 62, 80127 Naples, Italy (E-mail: vitomannacio2@libero.it).

J Thorac Cardiovasc Surg 2008;136:1541-8

$0022-5223 / \$ 34.00$

Copyright (c) 2008 by The American Association for Thoracic Surgery

doi:10.1016/j.jtcvs.2008.06.038
}

flammatory response has been demonstrated in the process leading to MD. ${ }^{10-13}$

Several clinical and experimental studies have suggested the usefulness of preoperative statin treatment in preventing MD after coronary artery bypass graft (CABG) surgery. ${ }^{14,15}$ 3-hydroxy-3-methyl-glutaryl-CoA (HMG-CoA) reductase inhibitors have been shown to significantly reduce cardiovascular risk independently of their lipid-lowering effect ${ }^{16,17}$ and to exert both a vasoprotective and an anti-inflammatory effect. ${ }^{18}$ Rosuvastatin (RSV) is a new-generation statin with a highly effective lipid-lowering and antiatherosclerotic activity. ${ }^{19,20}$ Its pharmacologic action has been shown at lower doses and with less collateral effects compared with other commonly used statins; however, only few data are available about its advantageous anti-inflammatory properties. ${ }^{16,19}$

We performed a randomized placebo-controlled trial of RSV pretreatment $(20 \mathrm{mg} / \mathrm{d})$ before elective coronary artery bypass surgery, investigating the possible effect of a 7-day preoperative statin treatment on reducing postoperative release of markers of MD.

\section{MATERIALS AND METHODS \\ Patient Population and Study Design}

This was a randomized, double-blind, placebo-controlled study. Between January 2005 and January 2007, 200 consecutive patients matching the study selection criteria were enrolled of a total of 1187 patients undergoing CABG surgery in the same period. Exclusion criteria were as follows to obtain as homogeneous a group as possible and therefore avoid any 


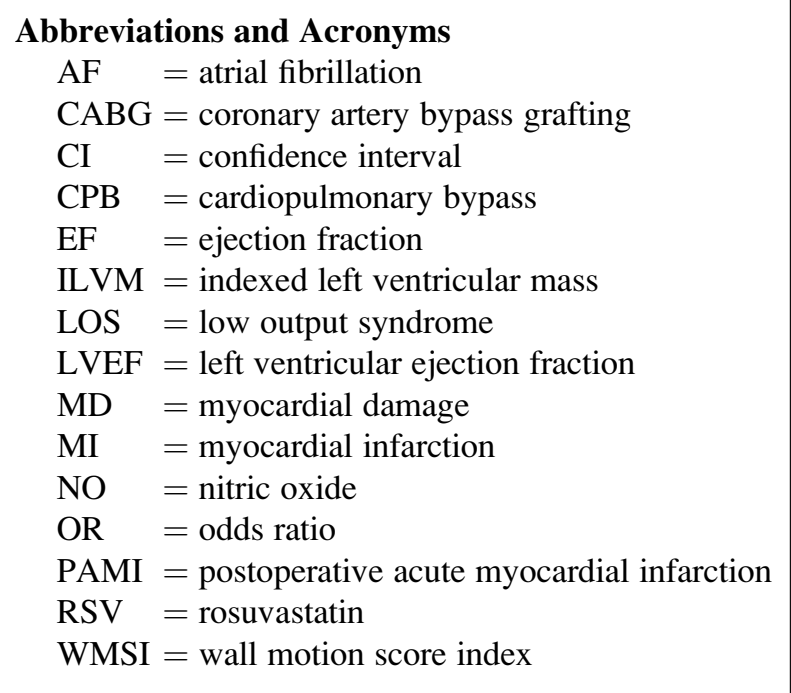

misleading interference: emergency cardiac operation; associated cardiac surgery; acute MI ( $<3$ months); poor cardiac function, as indicated by an ejection fraction (EF) less than $35 \%$; increase in creatine kinase-MB mass (CK-MB mass), troponin I, or myoglobin values before the operation; high-sensitivity C-reactive protein (hsCRP) levels of greater than $5 \mathrm{mg} / \mathrm{L}$ as a marker of acute or chronic preoperative inflammatory response; moderate renal failure (creatinine clearance $>2.0 \mathrm{~mL} \cdot \mathrm{min}^{-1} \cdot \mathrm{m}^{-2}$ ) ; active liver disease or increased liver enzyme levels (alanine aminotransferase - aspartate aminotransferase); type 2 diabetes mellitus; contraindications to statin treatments (history of liver or muscle disease); previous recent (60 days) therapy with steroidal or nonsteroidal anti-inflammatory drugs; and previous recent (30 days) treatment with any kind of statins: all patients who could not suspend the therapy for at least 30 days before the planned operation were excluded. Diabetic patients were excluded as well because their chronic inflammatory status might have interfered with measured hsCRP values at baseline. ${ }^{21,22}$ Patients undergoing surgical intervention for single- or quadruple-vessel disease were also excluded to avoid too high a variance between minimal and maximal cardiopulmonary bypass (CPB) time. ${ }^{23}$ Patients with diffuse distal lesions of the left anterior descending coronary artery, a dominant right coronary artery, and/or a dominant circumflex artery were also excluded. All patients received complete myocardial revascularization. The study cohort was very homogeneous for age, sex, clinical features, and severity of coronary artery disease.

According to the study design, 100 patients were randomized to placebo and 100 to RSV; the 2 patient groups were homogeneous, with minimal interference of minor demographic variables. All patients in the RSV group received a dose of $20 \mathrm{mg} / \mathrm{d}$ starting 7 days before the planned operation, regardless of cholesterol level. The dose was determined in agreement with the clinical pharmacology service, aiming at a satisfactory preoperative blood level of the drug with the lowest possible chance of disturbing collateral effects. Selection of patients for placebo or RSV treatment was obtained on admission by means of a computer-generated algorithm. Randomization was fully blinded, without any account of clinical or demographic features.

Hemodynamic variables were recorded in all patients through a SwanGanz Combo pulmonary artery catheter and elaborated with a Vigilance CEDV monitor (Edwards Lifesciences, Irvine, Calif). All surgical operations were performed by the same staff of senior surgeons. During the period of study, standardized operative techniques were always used, and a shared strategy was established before the operation. All operations were performed through a median sternotomy and during CPB with hollow-fiber oxygenators (Capiox SX25RX; Terumo, Leuven, Belgium) and roller pumps.
In all cases the ascending aorta and right atrium were cannulated. Pump flow was kept at approximately $2.5 \mathrm{~L} \cdot \mathrm{min}^{-1} \cdot \mathrm{m}^{-2}$, providing an arterial pressure of approximately $70 \mathrm{~mm} \mathrm{Hg}$. Normothermia was always used, and cardioplegic arrest was achieved with intermittent cold hyperkalemic blood cardioplegia infused into the ascending aorta. Retrograde cardioplegia was never used. Heparin was administered to obtain an activated clotting time of longer than 500 seconds. At the end of CPB, protamine sulfate was administered to completely reverse the heparin effect. The number of grafts per patient was 2 to 3 . The left internal thoracic artery was used in all cases and always to revascularize the left anterior descending artery. In 20 cases sequential grafting to the first diagonal artery was also performed. The right internal thoracic artery was also used in 70 patients younger than 60 years. Autologous saphenous veins were used in all other cases. The radial artery was never used. Graft flow was in all cases measured by means of a transittime flowmeter (CardioMed CM 2005; MediStern AS, Oslo, Norway) to confirm graft patency at the end of the procedure: in 8 cases the distal anastomosis had to be redone because of an unsatisfactory measured flow. Shed mediastinal blood was never autotransfused. No associated procedures were ever required.

A standardized protocol was followed in the intensive care unit. Blood transfusions were administered when hemoglobin values decreased to less than $8 \mathrm{~g} / \mathrm{dL}$. Ticlopidine was started 48 hours after the operation at a dose of $250 \mathrm{mg} / \mathrm{d}$ in both randomized groups. Other drugs were administered after the operation, when clinically indicated.

Twelve-lead electrocardiograms were obtained before the operation, on admission to the intensive care unit, 12 hours later, and every day thereafter until hospital discharge. The electrocardiograms were analyzed blind to the assigned treatment.

Echocardiographic evaluation was also obtained blind to the assigned treatment and was performed by the same 2 physicians preoperatively, 24 hours and 48 hours postoperatively, and at hospital discharge: left ventricular EF (LVEF), wall motion score index (WMSI), and indexed left ventricular mass (ILVM) were calculated and recorded. An ILVM of greater than $125 \mathrm{~g} / \mathrm{m}^{2}$ was considered a marker of left ventricular hypertrophy. A $5 \%$ or greater postoperative reduction of LVEF was considered significant. ${ }^{21}$

Blood samples for assay of CK-MB mass, troponin I, and myoglobin were collected before the operation and at 8, 12, 16, and 24 hours after the operation and then on every postoperative day until hospital discharge. Further testing was performed when the clinical picture suggested myocardial ischemia. The upper normal limits for assayed markers were defined according to the Joint European Society of Cardiology/American College of Cardiology guidelines. ${ }^{24}$ Upper normal limits were $5 \mathrm{ng} / \mathrm{mL}$ for CPK-MB, $0.08 \mathrm{ng} / \mathrm{mL}$ for troponin I, and $80 \mathrm{ng} / \mathrm{mL}$ for myoglobin. Troponin I, myoglobin, and CK-MB mass were assayed by means of a LIAISON kit (DiaSorin SpA, Saluggia, Italy), with a detection limit of less than 0.5 for myoglobin and CK-MB mass and less than 0.005 for troponin I.

hsCRP was assayed at baseline and at 24,48 , and 72 hours after the operation by means of immunonephelometry with a BN System (CardioPhase hs CRP-BN ProSpec; Dade Behring Marburg GmbH, Marburg, Germany). Levels of hsCRP of $3 \mathrm{mg} / \mathrm{L}$ or less were considered to be normal. When a value of greater than $5 \mathrm{mg} / \mathrm{L}$ was obtained, the test was repeated to avoid any inappropriate interpretation.

Two weeks after hospital discharge, all patients were followed up during an office visit.

\section{Definition of Perioperative Data}

Before starting the study, we proceeded to the necessary assessment of the concept and definition of postoperative acute myocardial infarction (PAMI) versus MD. As confirmed by several reports, high serum levels of cardiac enzymes can be detected in more than $60 \%$ of patients after cardiac surgery, even in the absence of electrocardiographic evidence, echocardiographic evidence, or both of MI. Therefore it was imperative for us to establish a cutoff level between PAMI and MD. 
We accepted that, as indicated by the Joint European Society of Cardiology/American College of Cardiology guidelines, ${ }^{24}$ a number of different criteria must be met for a perioperative MI to be diagnosed: (1) indicative electrocardiographic changes (ST-T changes, new Q-wave appearance, and reduction of $\mathrm{R}$ waves greater than $25 \%$ in at least 2 leads); (2) echocardiographic evidence of new akinetic/dyskinetic ventricular wall segments; and (3) biochemical indicators (maximal concentration of troponin I and maximal value of CK-MB mass exceeding the 99th percentile of the value for the referenced controlled group on 2 subsequent samples or maximal value exceeding 5 times the normal upper limits on 1 occasion). Therefore we never considered the laboratory evidence of an increased biomarker serum level without evidence of the other 2 criteria as indicative of PAMI.

Increased levels of hsCRP $(>5 \mathrm{mg} / \mathrm{L})$ were always considered consistent with a significant inflammatory response.

Postoperative renal failure was defined as an increase in serum creatinine value of greater than $2.5 \mathrm{mg} / \mathrm{dL}$.

Low output syndrome (LOS) was diagnosed when cardiac index decreased to less than $2.0 \mathrm{~L} \cdot \mathrm{min}^{-1} \cdot \mathrm{m}^{-2}$, pulmonary capillary wedge pressure exceeded $15 \mathrm{~mm} \mathrm{Hg}$, left ventricular stroke work index decreased to less than $22 \mathrm{~g} \cdot \mathrm{m}^{-1} \cdot \mathrm{m}^{-2}$, and results of mixed systemic venous oxymetry were less than $60 \%$ for at least 30 minutes after correction of all electrolyte or blood gas abnormalities and after preload optimization. Patients needing less than $5 \mu \mathrm{g} / \mathrm{kg}$ dopamine or dobutamine were not considered to be in LOS.

The study protocol was approved by the ethics committee of our institution and by the hospital's institutional review board. Informed consent was obtained from each patient before enrollment in the study.

\section{End Points}

The primary end point of this study was the incidence of postoperative MD in the 2 trial arms. Secondary end points were (1) relationships between MD and any possible demographic and clinical features evaluating the effect of RSV therapy on these variables and (2) assessment of different kinds of increasing curves of troponin I in the 2 arms.

\section{Statistical Analysis}

As previously reported in observational and randomized studies, evidence of postoperative MD can be observed in about $60 \%$ to $80 \%$ of cases of surgical intervention for CABG. Recent investigations suggest that preoperative treatment with statins can reduce the incidence of MD by $40 \%$ to $70 \%$. Therefore our study enrolled a total sample of 200 patients (100 in each group) to obtain a statistical power of more than $90 \%$ to detect a probability of .05 . Continuous variables were expressed as means \pm standard deviation and categorical data as proportions. Comparison between continuous variables in the 2 groups was made by means of Student's $t$ test for normally distributed features values. The Mann-Whitney $U$ test was used for variables not normally distributed (biomarker values). Categorical variables were analyzed with the $\chi^{2}$ test or Fisher's exact test, when required. Analysis of risk factors for perioperative MD was performed, calculating the odds ratio (OR) with a $95 \%$ confidence interval (CI). Variables with $P$ values of less than .01 were considered significant and were analyzed in a multivariate logistic regression model to assess the effect of each risk factor on perioperative MD. A linear regression equation for troponin I level over time was built for evaluating marker slopes in the 2 groups. For all statistical tests, a $P$ value of less than .01 was indicative of a significant difference. Statistical analyses were performed by using the SPSS program for Windows (SPSS, Chicago, Ill).

The authors had full access to the data and take responsibility for its integrity. All authors have read and agree to the manuscript as written.

\section{RESULTS}

Tables 1 and 2 show demographic and perioperative variables in the 2 groups. They are homogeneous for age, sex,
TABLE 1. Clinical population in the placebo and Rosuvastatin Group

\begin{tabular}{|c|c|c|c|}
\hline Characteristic & $\begin{array}{l}\text { Placebo } \\
(\mathbf{n}=100)\end{array}$ & $\begin{array}{c}\text { RSA } \\
(\mathbf{n}=\mathbf{1 0 0})\end{array}$ & $P$ \\
\hline Male, n (\%) & 70 & 75 & 0.4 \\
\hline Age, y & $59.3 \pm 8.4$ & $61.3 \pm 9.2$ & 0.8 \\
\hline Body Surface Area (BSA) & $1.83 \pm 0.2$ & $1.88 \pm 0.18$ & 0.06 \\
\hline Systemic Hypertension & 21 & 25 & 0.6 \\
\hline Stable Coronary Disease & 68 & 73 & 0.5 \\
\hline $\begin{array}{l}\text { Previous Myocardial } \\
\text { Infarction }\end{array}$ & 25 & 21 & 0.6 \\
\hline $\begin{array}{l}\text { Previous Coronary } \\
\text { Angioplasty }\end{array}$ & 8 & 10 & 0.8 \\
\hline Double Vessel Disease & 55 & 50 & 0.57 \\
\hline Triple Vessel Disese & 45 & 50 & 0.23 \\
\hline Low-density lipoprotein & $127 \pm 21$ & $121 \pm 28$ & 0.08 \\
\hline Blood Creatinine & $1.5 \pm 0.5$ & $1.4 \pm 0.4$ & 0.1 \\
\hline $\begin{array}{l}\text { Left Ventricular Ejection } \\
\text { Fraction }>60 \%\end{array}$ & 51 & 60 & 0.2 \\
\hline $\begin{array}{l}\text { Left Ventricular Ejection } \\
\text { Fraction }<60 \%\end{array}$ & 49 & 40 & 0.2 \\
\hline Wall Motion Score Index & $1.18 \pm 0.14$ & $1.23 \pm 0.38$ & 0.37 \\
\hline $\begin{array}{l}\text { Indexed Left Ventricular } \\
\text { Mass }\end{array}$ & $104.9 \pm 25.2$ & $110.6 \pm 21.4$ & 0.08 \\
\hline \multicolumn{4}{|l|}{ Medical therapy } \\
\hline$\beta$-Blockers & 68 & 73 & 0.5 \\
\hline ACE Inhibitors & 28 & 22 & 0.4 \\
\hline Calcium Antagonists & 27 & 30 & 0.7 \\
\hline Amjodarone & 12 & 10 & 0.8 \\
\hline
\end{tabular}

clinical history, coronary lesions, preoperative echocardiographic features, and medical therapy. Low-density lipoprotein levels before the operation were $121 \pm 28 \mathrm{mg} / \mathrm{dL}$ in the RSV group versus $127 \pm 21 \mathrm{mg} / \mathrm{dL}$ in the placebo group $(P=.08)$. Surgical procedures, mean number of grafts per patient, and CPB and aortic crossclamping times were also similar. A postoperative low dose of inotropic support

TABLE 2. Surgical Features

\begin{tabular}{lccc}
\hline \multicolumn{1}{c}{ Characteristic } & $\begin{array}{c}\text { Placebo } \\
(\mathbf{n = 1 0 0})\end{array}$ & $\begin{array}{c}\text { RSA } \\
(\mathbf{n = 1 0 0})\end{array}$ & $\boldsymbol{P}$ \\
\hline Mean Grafts/patients & $2.45 \pm 0.49$ & $2.5 \pm 0.5$ & 0.45 \\
Left internal Mammary Area Grafts & 99 & 100 & 0.98 \\
Right internal Mammary & 32 & 38 & 0.4 \\
$\quad$ Area Grafts & & & \\
CPB time, min & $83.8 \pm 25.2$ & $80.6 \pm 22.4$ & 0.3 \\
Cross Clamp Time, min & $40.3 \pm 18$ & $42.2 \pm 19.2$ & 0.4 \\
Postoperative Low Output & 1 & 1 & \\
$\quad$ Syndrome & & & \\
Postoperative inotropic support & 25 & 11 & 0.001 \\
Postoperative IABP Assistance & 1 & 0 & \\
Postoperative Renal Failure & 3 & 1 & 0.6 \\
Postoperative Myocardial Infarction & 2 & 1 & 1 \\
Postoperative Hospitalization, mean & $9.1 \pm 1.4$ & $8.2 \pm 1.2$ & $<0.001$ \\
Postoperative atrial fibrillation & 35 & 18 & 0.001 \\
Mean ventricular response & $123 \pm 15$ & $119 \pm 11$ & 0.3 \\
\hline
\end{tabular}


TABLE 3. Postoperative biochemical features

\begin{tabular}{lccccc}
\hline & \multicolumn{2}{c}{ Placebo } & & \multicolumn{2}{c}{ RSV } \\
\cline { 2 - 4 } & $\mathbf{n}=\mathbf{1 0 0}$ & Mean peak values & & $\mathbf{n}=\mathbf{1 0 0}$ & Mean peak values \\
\hline Troponin I & $65 \%$ & $0.32 \pm 0.26 \mathrm{ng} / \mathrm{mL}$ & & $35 \%$ & $0.16 \pm 0.15 \mathrm{ng} / \mathrm{mL}$ \\
Myoglobin & $72 \%$ & $98.31 \pm 31 \mathrm{ng} / \mathrm{mL}$ & & $39 \%$ & $72.25 \pm 25 \mathrm{ng} / \mathrm{mL}$ \\
CK-MB mass & $40 \%$ & $9.3 \pm 8.1 \mathrm{ng} / \mathrm{mL}$ & & $22 \%$ & $3.9 \pm 3.3 \mathrm{ng} / \mathrm{mL}$ \\
hsCRP & $88 \%$ & $17.2 \pm 3.4 \mathrm{mg} / \mathrm{L}$ & $58 \%$ & $<.001$ \\
\hline
\end{tabular}

$R S V$, Rosuvastatin; $C K-M B$, creatine kinase-MB; $h S C R P$, high-sensitivity C-reactive protein.

( 3 to $5 \mu \mathrm{g} \cdot \mathrm{kg}^{-1} \cdot \mathrm{min}^{-1}$ ) was needed by 25 patients in the placebo group versus 11 in the RSV group $(P=.001)$. PAMI occurred in 2 patients in the placebo group; one had an LOS that was successfully treated with intra-aortic balloon assistance. Only 1 patient in the RSV group had evidence of PAMI. Transient postoperative renal failure occurred in $3 \%$ of patients in the placebo group versus $1 \%$ in the RSV group. Mean preoperative values of CK-MB mass, troponin I, myoglobin, and hsCRP were similar in the 2 compared groups. Postoperative biochemical features are reported in Table 3. Significant postoperative increases in troponin I $(65 \%$ vs $35 \%, P<.0001)$, myoglobin $(72 \%$ vs $39 \%, P<.0001)$, and CK-MB mass $(40 \%$ vs $22 \%, P=$ $.0002)$ values were observed in the placebo group. Mean postoperative peak values of all markers were lower in the RSV group: troponin I, $0.16 \pm 0.15$ versus $0.32 \pm 0.26$ $\mathrm{ng} / \mathrm{mL}(P=.0008)$; myoglobin, $72.25 \pm 25$ versus 98.31 $\pm 31 \mathrm{ng} / \mathrm{mL}(P<.0001)$; CK-MB mass, $3.9 \pm 3.3$ versus $9.3 \pm 8.1 \mathrm{ng} / \mathrm{mL}(P<.0001)$. An increased hsCRP level was observed in all cases of MD but less frequently in the RSV group than in the placebo group $(15.4 \pm 2.5$ vs 17.2 $\pm 3.4 \mathrm{mg} / \mathrm{L}, P<.0001)$.

Postoperative atrial fibrillation (AF) occurred in 18 patients in the RSV group versus 35 in placebo group $(P=.001)$, and mean ventricular response was $119 \pm 11$ beats/min in the RSV arm and $123 \pm 15$ beats/min in the placebo arm. Intravenous infusion of amiodarone restored normal sinus rhythm in all cases. Treatment with RSV was associated with a $44 \%$ reduction in risk of AF (OR, 0.46; 95\% CI, 0.22-094; $P=.03$ ). A postoperative hsCRP level of greater than $15 \mathrm{mg} / \mathrm{L}$ was associated with a higher probability of $\mathrm{AF}(\mathrm{OR}, 2.0 ; 95 \% \mathrm{CI}, 1.2-7.0$; $P=.001)$.

Postoperative echocardiographic evaluation showed an LVEF of less than $30 \%$ and an WMSI of greater than 1.15 in those patients who had LOS, PAMI, or both. In 11 of the remaining patients under investigation, predischarge WMSI values were not obtained because of inadequate image quality; however, in all other cases, the WMSI value remained similar to the preoperative one. A $5 \%$ to $8 \%$ LVEF reduction from the preoperative measured values was detected in only 11 cases over the whole enrolled population; it appeared to be equally distributed in the 2 arms of the study (6 in the RSV group vs 5 in the placebo group, $P=$
.98) and to be independent from the occurrence of MD ( 3 in the RSV group vs 3 in the placebo group). In all cases postoperative ILVM values remained unmodified.

A higher incidence of MD was observed in some subgroups of the patient population ( $>65$ years of age, menopause, history of previous MI, EF $<45 \%$ or ventricular hypertrophy at echocardiographic analysis, and crossclamp time $>110$ minutes). In particular, troponin I, myoglobin, and CK-MB mass values were increased in $31(81.6 \%)$ of 38 of aged patients in the placebo group versus 20 $(57.1 \%)$ of 35 in the RSV group $(P=.0004)$. Among the aged patients, women showed high values in $16(84.2 \%)$ of 19 cases versus $14(63.6 \%)$ of 22 cases among men $(P=.0001)$. In patients with left ventricular hypertrophy, high values were observed in $15(83.3 \%)$ of 18 patients versus $12(57.1 \%)$ of 21 patients without hypertrophy $(P<.0001)$. Among patients with EFs of less than $45 \%$, high values occurred in $15(83.3 \%)$ of 18 patients versus $13(56 \%)$ of 23 patients among the group with EFs of greater than $45 \%(P<.0001)$. Among patients with a history of MI, high values were observed in $22(88 \%)$ of 25 patients versus $15(71.4 \%)$ of 21 patients in the absence of a history of MI $(P=.0005)$. Finally, biomarker levels increased in 22 $(80.3 \%)$ of 28 patients with prolonged crossclamp times (>110 minutes) versus $15(50 \%)$ of 30 patients without long crossclamp times $(P=.0001$, Figure 1$)$. When MD

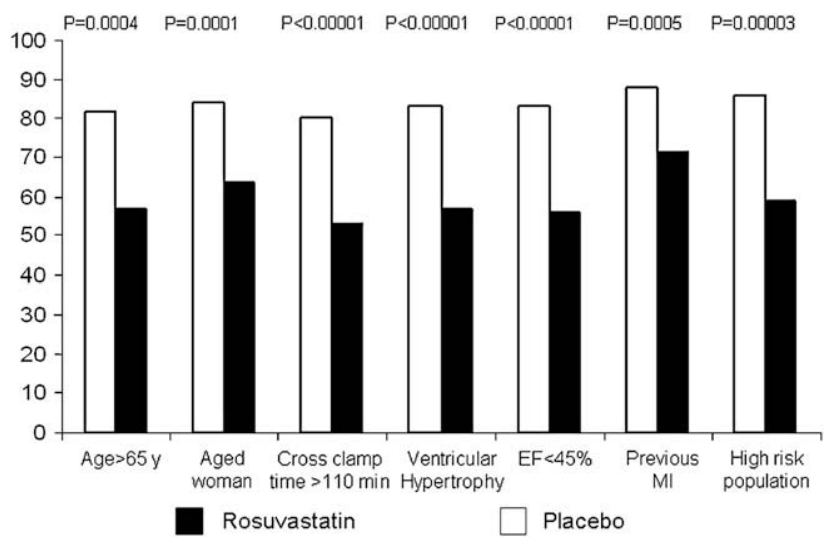

FIGURE 1. Rate of postoperative myocardial disease in high-risk patients. The last column shows cumulative results in high-risk patients of the 2 study arms. $E F$, Ejection fraction; $M I$, myocardial infarction. 


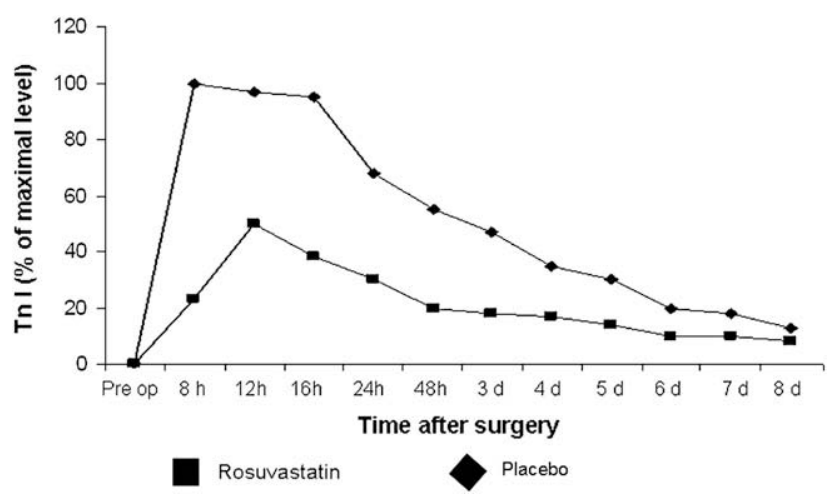

FIGURE 2. Mean plasma troponin I ( $T n I)$ changes after cardiac surgery as a percentage of maximal level.

occurred, troponin I levels peaked at 8 hours after the operation in the placebo group, with a mean peak level of $0.32 \pm$ $0.26 \mathrm{ng} / \mathrm{mL}$, and at 12 hours in the RSV group, with a mean peak level of $0.16 \pm 0.15 \mathrm{ng} / \mathrm{mL}$. As far as slope diagrams are concerned, only the troponin I diagram was taken into account because it has been shown to be associated with the highest specificity and sensitivity. Up-slope steepness of the postoperative troponin I curve appeared to be less in the RSV group than in the placebo group. Statistical significance could not be calculated in the ascending graph because of the small number of time points, but down-slope steepness in the placebo group was significantly less than in the RSV group (slope steepness of postoperative troponin I was -0.91 in the RSV group vs -0.51 in the placebo group, $t=3.47, d f=8, P<.01$, Figure 2). Mean postoperative hospitalization time was significantly shorter in the RSV group than in the placebo group $(9.1 \pm 1.4$ days vs $8.2 \pm 1.2$ days, $P<.0001)$. Multivariate logistic regression analysis identified advanced age, advanced age in women, previous MI, low preoperative ejection fraction, ventricular hypertrophy, and aortic crossclamp time of longer than 110 minutes as independent predictors of MD. When only this subgroup of patients was analyzed, the observed incidence of MD was $86 \%$ in the placebo group versus $58.9 \%$ in the RSV group $(P<.0001)$. At any rate, MD was always significantly reduced by pretreatment with RSV (OR, $0.23 ; 95 \% \mathrm{CI}$, 0.11-0.49; Figure 3).

\section{DISCUSSION}

This is the first randomized study showing that pretreatment with RSV decreases the incidence of MD compared with that after placebo in patients undergoing coronary surgery with $\mathrm{CPB}$. Interpretation of evidence of biomarker increase without changes in cardiac function is still a controversial issue. Many reports found a correlation between evidence of MD and the prevalence of late cardiac events. ${ }^{9,25-27}$ According to data from the available literature, an absolute reduction of marker release, as observed in the present study, would translate into a reduction of early and late adverse events. ${ }^{28}$ Many articles suggest beneficial effects from statin treatment in patients undergoing coronary percutaneous interventions ${ }^{29}$; however, only a few reports confirmed similar results in patients undergoing coronary surgery. ${ }^{30,31}$ Lazar and colleagues, ${ }^{14}$ in their experimental study, demonstrated that a 3-week pretreatment with atorvastatin $(40 \mathrm{mg} / \mathrm{d})$ enhanced myocardial protection in pigs during surgical revascularization for acutely induced myocardial ischemia when compared with the effect of placebo pretreatment. Clark and associates ${ }^{15}$ reported long-term beneficial clinical effects on mortality and morbidity from statin pretreatment before coronary surgery. However, this was a retrospective study, and different types of statins were used at variables doses.

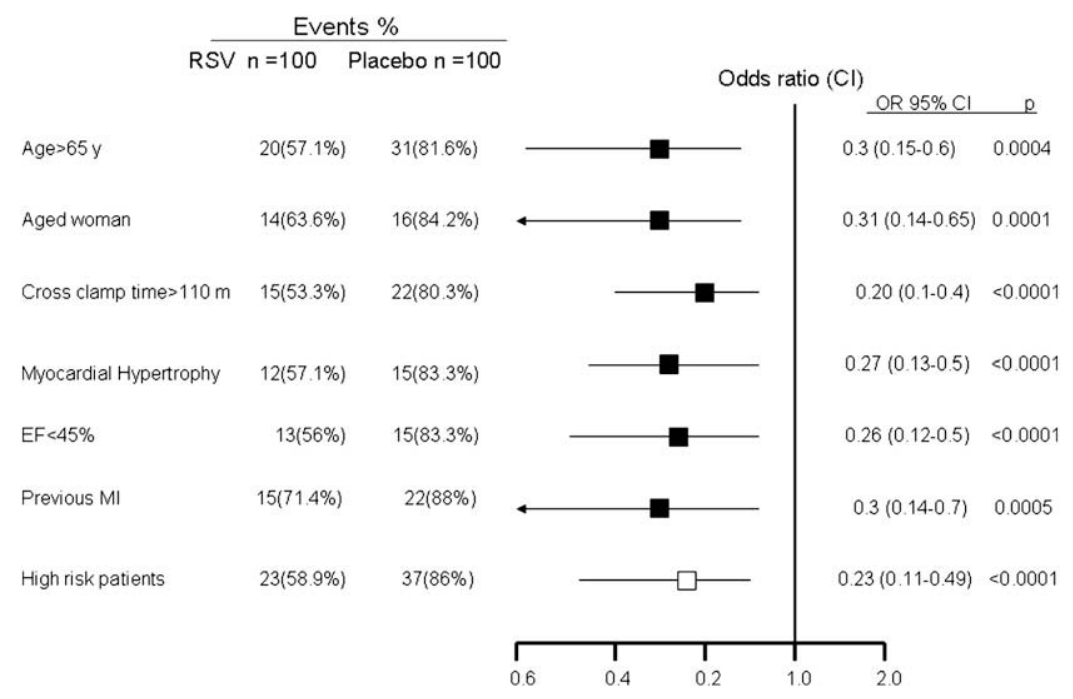

FIGURE 3. Results of multivariate analysis showing the effect of rosuvastatin $(R S V)$ pretreatment in high-risk patients. $O R$, Odds ratio; $C I$, confidence interval; $E F$, ejection fraction; $M I$, myocardial infarction. 
The present study is the first randomized double-blind trial that followed strict enrollment criteria to obtain 2 very homogeneous randomized study arms. Any misleading interference was removed as much as possible, and patients were treated with the same statin at the same doses along a similar extent of preoperative time. Univariate and multivariate analysis of our results confirmed the protective effects of RSV pretreatment on the incidence of MD in patients undergoing coronary surgery with $\mathrm{CPB}$. As regards the observed protective effect against MD, metabolic pathways influenced by statin pretreatment are still under experimental investigation. However, a number of recent reports suggest a link between their protective effects and an enhanced expression of endothelial nitric oxide (NO), as well as a significant reduction in endogenous peroxide concentration and peroxidase activity. ${ }^{32-35}$ Laufs and coworkers ${ }^{36}$ have shown that statins improve the stability of mRNA responsible for endothelial cell NO synthase and increase the half-life of the mRNA responsible for endothelial cell NO synthase synthesis from 13 to 18 hours with enhanced production of NO at the endothelial level. In endothelial dysfunction, impaired synthesis of NO might give rise to an inflammatory reaction, with increased platelet and leucocyte adhesion and local flow reduction. ${ }^{37}$ This study confirms the previous finding that $\mathrm{CPB}$ is associated with significant inflammatory response, as evidenced by increased values of hsCRP in patients of the placebo group and substantially lower values in the case of RSV pretreatment. In all cases of MD in both arms of the study, we observed high level of hsCRP, which supports the conclusion that an inflammatory response is always active in cases of MD.

The statins' anti-inflammatory effects and protective activity against tissue injury were largely associated with a significant reduction in the risk of AF onset after coronary surgery. ${ }^{38,39}$ In the present study postoperative hsCRP levels of greater than $15 \mathrm{mg} / \mathrm{L}$ were associated, in multivariate analysis, with a higher probability of $\mathrm{AF}$ in either group, and RSV pretreatment was established as the only factor influencing the postoperative incidence of $\mathrm{AF}$, providing a $44 \%$ risk reduction. Our study suggests the incidence of $\mathrm{AF}$ as strictly connected to biochemical evidence of MD and provides evidence indicating that inflammation and endothelial disease are of utmost importance in the development of postoperative AF after coronary surgery. ${ }^{38}$

A final relevant finding in our study was the higher incidence of MD in a subgroup of our patient population defined as high-risk patients (age $>65$ years, menopause, previous $\mathrm{MI}$ in the history, preoperative $\mathrm{EF}<45 \%$ or ventricular hypertrophy at echocardiography, and aortic crossclamping time $>110$ minutes). These patients exhibited a significantly greater marker leakage compared with other non-high-risk patients belonging to the same arm of the study. Even in this subpopulation, however, RSV pretreatment provided a significant reduction in the occurrence of MD and in the need for early postoperative inotropic support. Evidence from this study strongly supports the advantage of statin pretreatment before coronary surgery with $\mathrm{CPB}$, particularly in high-risk patients. Pathophysiologic phenomena involved in MD are still under scrutiny, but all evidence indicates limited bioavailability of $\mathrm{NO}$ in senescence, especially in woman in menopause because of loss of the antiaging action of estrogens. ${ }^{40}$ A similarly impaired NO metabolism can be proposed as operative in hypertrophic hearts, in case of previous MI, and in any stress situation marked by reduced flow.

In conclusion, our results confirm the high incidence of perioperative $\mathrm{MD}$ in patients undergoing $\mathrm{CABG}$ and the protective effect of pretreatment with $20 \mathrm{mg} / \mathrm{d}$ RSV starting 7 days before the operation and continuing through the postoperative period. RSV decreases the incidence of MD and reduces the inflammatory response to $\mathrm{CPB}$ without treatment-related complications. This randomized trial, enrolling only selected patients, presents some intrinsic limitations: (1) long-term event-driven studies are needed to assess the advantage of preoperative statin therapy on long-term outcome; (2) our results must be confirmed in a larger population of patients, including diabetic patients, unstable patients, and patients with extensive coronary artery disease and decreased LVEF, which are more reflective of the common surgical population; and (3) not all patients who underwent coronary surgery can have 7 days before the operation to be treated with statins. However, we believe that widespread use of statins must be encouraged, when possible, in patients undergoing coronary surgery to prevent MD.

\section{References}

1. Noora J, Ricci C, Hasting D, Hill S. Cybulsky. Determination of troponin release after CABG surgery. J Card Surg. 2005;20:129-35.

2. Sadony V, Korber M, Albes G, Podtschaske V, Etgen T, Trosken T, et al. Cardiac troponin I levels for diagnosis and quantization of perioperative myocardial damage in patients undergoing coronary artery bypass surgery. Eur J Cardiothorac Surg. 1998;13:57-65.

3. Etievent JP, Chocron S, Toubin G, Taberlet C, Alwan K, Clement F, et al. Troponin I as a marker of perioperative myocardial ischemia. Ann Thorac Surg. 1995; 59:1192-4.

4. Jacquet L, Noirhomme P, El Khoury G, Goenen M, Philippe M, Col J. Cardiac troponin I as early marker of myocardial damage after coronary artery bypass surgery. Eur J Cardiothorac Surg. 1998;13:378-84.

5. Horvath KA, Parker MA, Frederiksen JW, Palmer AS, Fullerton DA. Postoperative troponin I values: insult or injury? Clin Cardiol. 2000;32:731-5.

6. Abramov D, Talilakh MA, Frieger M, Ganiel A, Tuvbin D, Wolak A. Plasma troponin level after cardiac surgery vs after myocardial infarction. Asian Cardiovasc Thorac Ann. 2006; 14:530-5.

7. Botha P, Nagaraja DP, Lewis PS, Dunning J. Can cardiac troponins be used to diagnose a perioperative myocardial infarction after cardiac surgery? Interact Cardiovasc Thorac Surg. 2004;3:442-9.

8. Alexander JH, Sparapani RA, Mahaffey KW, Deckers JW, Newby LH, Ohman EM, et al. Association between minor elevation of creatine kinase-MB level and mortality in patients with acute coronary syndromes without ST-segment elevation. JAMA. 2000;283:347-53

9. Onorati F, De Feo M, Mastroroberto P, Cristodoro L, Pezzo F, Renzulli A, et al. Determinants and prognosis of myocardial damage after coronary artery bypass grafting. Ann Thorac Surg. 2005;79:837-45. 
10. Yeh ETH, Anderson HV, Pasceri V, Willerson T. C reactive protein: linking inflammation to cardiovascular complications. Circulation. 2001;104:974-5.

11. Libby P. Molecular bases of acute coronary syndromes. Circulation. 1995;91: 2844-50.

12. Du Clos TW. Function of C-reactive protein. Ann Med. 2000;32:274-8.

13. Pasceri V, Chang J, Willerson JT, Yeh ETHI. Modulation of C reactive proteinmediated monocyte chemoattractant protein 1 induction in human endothelial cells by anti-atherosclerosis drugs. Circulation. 2001;103:2531-4.

14. Lazar HL, Bao Y, Zhang Y, Bernard SA. Pretreatment with statins enhance myocardial protection during coronary revascularization. $J$ Thorac Cardiovasc Surg. 2003; $125: 1037-42$.

15. Clark LL, Ikonomidis JS, Crawford FA, Crumbley A, Kratz JM, Stroud MR. Preoperative statin treatment is associated with reduced postoperative mortality and morbidity in patients undergoing cardiac surgery: an 8-year retrospective cohort study. J Thorac Cardiovasc Surg. 2006;131:679-85.

16. Kleeman R, Princen HMG, Emeis JJ, Jukema W, Fontijn RD, Horrevoets AJG, et al. Rosuvastatin reduces atherosclerosis development beyond and independent of its plasma cholesterol-lowering effect in APOE 3-Liden transgenic mice. Circulation. 2003;108:1368-74.

17. Wilson SH, Simari RD, Best PG, Peterson TE, Lerman LO, Aviram R, et al. Sinvastatin preserves coronary endothelial function in hypercholesterolemia in the absence of lipid lowering. Arterioscer Thromb Vasc Biol. 2001; 21:122-8.

18. Ridker PM, Rifai N, Pfeffer MA, Sacks F, Braumwald E. Long term effect of pravastatin on plasma concentration of C-reactive protein: the Cholesterol And Recurrent Events (CARE) Investigators. Circulation. 1999;100:230-5.

19. Resch U, Tatzeber F, Budinsky A, Senzinger H. Reduction of oxidative stress and modulation of autoantibodies against modified low density lipoprotein after rosuvastatin therapy. Br J Clin Pharmacol. 2006;61:262-74.

20. Jones S, Gibson M, Rimmer D, Gibson T, Sharp B, Lefer D. Direct vascular and cardioprotective effects of rosuvastatin, a new HMG-CoA reductase inhibitor. J Am Coll Cardiol. 2002;40:1172-8.

21. Beishuizen ED, Tamsma JT, Jukama JW, Van de Ree M, Van der Vijver JCM, Meinders AE, et al. The effect of statin therapy and endothelial function in type 2 diabetes without manifest cardiovascular disease. Diabetes Care. 2005;28: 1668-74.

22. Schalkwisk CG, Poland DCW, Van Dijk W, Kok A, Emeis JJ, Drager AM, et al. Plasma concentration of C-reactive protein increases in type I diabetic patients without clinical microangiopathy and correlated with markers of endothelial dysfunction: evidence of chronic inflammation. Diabetologia. 1999;42: 351-7.

23. Schinkel AF, Poldermans D, Rizzallo V, Vanoverscheld JL, Elhendy A, Boersma E, et al. Why do patients with ischemic cardiomyopathy and a substantial amount of viable myocardium not always recover in function after revascularization? J Thorac Cardiovasc Surg. 2004;127:385-90.

24. Alpert JS, Thygensen K, Antman E, Bassand JP. Myocardial infarction redefined: a consensus document of the Joint European Society of Cardiology/American College of Cardiology Committee for the redefinition of myocardial infarction. J Am Coll Cardiol. 2000;36:959-69.
25. Benoit MO, Paris M, Silleran J, Fiemejer A, Moatti N. Cardiac troponin I: it contribution to the diagnosis of perioperative myocardial infarction and various complications of cardiac surgery. Thorac Cardiovasc Surg. 2001;49: 137-43.

26. Fellahi JL, Gue X, Richomme X, Monier M, Guillou L, Riou B. Short and long term prognostic value of troponin I concentration in patients undergoing coronary artery bypass grafting. Anesthesiology. 2003;99:270-4.

27. Jarvinen O, Julkunes J, Saarinen S, Laurikka J, Huhtala H, Tarkka MR. Perioperative myocardial infarction has negative impact on health-related quality of life following coronary artery bypass graft surgery. Eur J Cardiothorac Surg. 2004; 26:621-7.

28. Onorati F, Cristodoro L, Caroleo S, Esposito A, Amantea B, Santangelo E, et al. Troponin I and lactate for coronary sinus predict cardiac complications after myocardial revascularization. Ann Thorac Surg. 2007;83:1016-23.

29. Pasceri V, Patti G, Nusca A, Pristipino C, Richichi G, Di Sciascio G. Randomized trial on atorvastatin for reduction of myocardial damage during coronary intervention: results from the ARMYDA (Atorvastatin for Reduction of Myocardial Damage During Angioplasty) study. Circulation. 2004;110:674-8.

30. Greenson N, Macoviak J, Krishnaswamy P, Morrisey R, James C, Clopton P, et al. Usefulness of cardiac troponin I in patients undergoing open heart surgery. Am Heart J. 2001;141:447-55.

31. Bonnefoy E, Filley S, Kirkorian G, Guidollet J, Roriz R, Robin J, et al. Troponin I, troponin $\mathrm{T}$, or creatine kinase-MB to detect perioperative myocardial damage after coronary artery bypass surgery. Chest. 1998;114:482-6.

32. Drexler H, Hornig B. Endothelial dysfunction in human disease. J Mol Cell Cardiol. 1999;31:51-60.

33. Pesic S, Radenkovic M, Grbovic L. Endothelial dysfunction: mechanism of development and therapeutic options. Med Pregl. 2006;59:335-41.

34. Politarchou C, Papadimitriou E. Antioxidants inhibit human endothelial cell functions through down regulation of endothelial nitric oxide synthetase. Eur J Pharmacol. 2005;510:31-8.

35. Bulhak AA, Gourine AV, Gonon AT, Sjoquist PO, Valen G, Pernow J. Oral pretreatment with rosuvastatin protects porcine myocardium from ischemia/reperfusion injury via a mechanism related to nitric oxide but no serum cholesterol level. Acta Physiol Scand. 2005;183:151-9.

36. Laufs U, La Fata V, Plutzky J, Liao JK. Upregulation of endothelial nitric oxide synthase by HMG CoA reductase inhibitors. Circulation. 1998;97:1129-35.

37. Chello M, Mastroroberto P, Patti G, D'Ambrosio A, Morichetti MC, D Sciascio G, et al. Simvastatin attenuates leucocyte-endothelial interactions after coronary revascularization with cardiopulmonary bypass. Heart. 2003;89:538-43.

38. Engelman MDM, Svendsen JH. Inflammation in genesis and perpetual of atrial fibrillation. Eur Heart J. 2005;26:2083-92.

39. Lertsburapa K, While CM, Kluger J, Faheem O, Hammonds J, Coleman CI. Preoperative statin therapy for prevention of atrial fibrillation after thoracic surgery. $J$ Thorac Cardiovasc Surg. 2008;135:405-11.

40. Hayashi T, Matsui-Hirai H, Miyazaki-Akita A, Fukatsu A, Funami J, Ding QF, et al. Endothelial cellular senescence is inhibited by nitric oxide: implications in atherosclerosis associated with menopause and diabetes. Proc Natl Acad Sci U S A. 2006; 103:17018-23. 
Access to The Journal of Thoracic and Cardiovascular Surgery Online is reserved for print subscribers!

Full-text access to The Journal of Thoracic and Cardiovascular Surgery Online is available for all print subscribers. To activate your individual online subscription, please visit The Journal of Thoracic and Cardiovascular Surgery Online, point your browser to http://www.mosby.com/jitcvs, follow the prompts to activate your online access, and follow the instructions. To activate your account, you will need your subscriber account number, which you can find on your mailing label (note: the number of digits in your subscriber account number varies from 6 to 10 ). See the example below in which the subscriber account number has been circled:

\section{Sample mailing label}

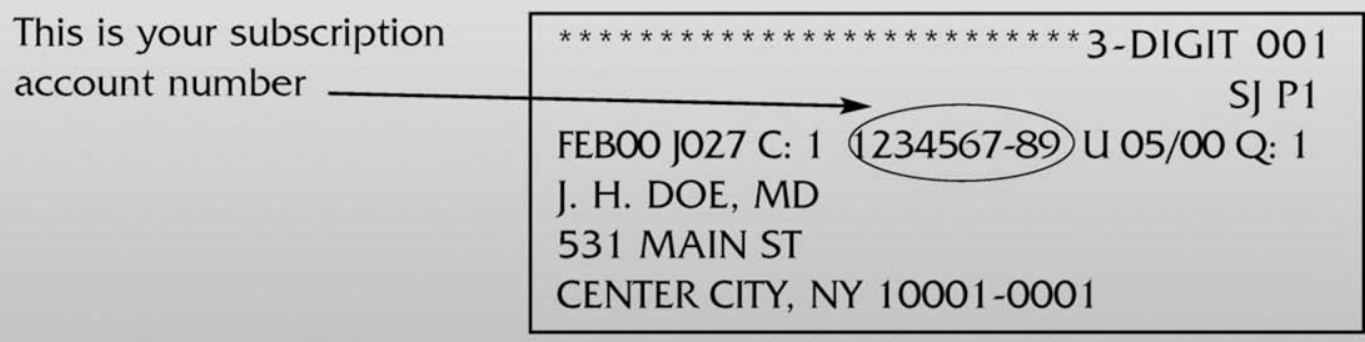

Personal subscriptions to The Journal of Thoracic and Cardiovascular Surgery Online are for individual use only and may not be transferred. Use of The Journal of Thoracic and Cardiovascular Surgery Online is subject to agreement to the terms and conditions as indicated online. 